Original Research Paper

\title{
Experimental and Numerical Analysis of Continuously Coupling Timber-Lightweight EPS Concrete Composite System
}

\author{
Nikola Perković, Vlatka Rajčić and Jure Barbalić \\ Faculty of Civil Engineering, University of Zagreb, Croatia
}

\author{
Article history \\ Received: 02-12-2020 \\ Revised: 30-01-2021 \\ Accepted: 02-02-2021 \\ Corresponding Author: \\ Nikola Perković \\ Faculty of Civil Engineering, \\ University of Zagreb, Croatia \\ Email: nikola.perkovic@grad.unizg.hr
}

\begin{abstract}
A composite system based on concrete and timber represents a very successful engineering solution in the process of optimization of construction. Nowadays, by combining different timber products and concrete classes it is easy to achieve improved engineering features for elements in different static systems or load cases. This paper presents an overview of the research initiated by solving the problem of the actual loadbearing capacity of the already built composite timber-EPS systems which based their calculation on the theory of coupling timber with normal concrete. The research was taken at the Faculty of Civil Engineering, the University of Zagreb to define the behavior of timber-Extruded Polystyrene (EPS) lightweight concrete composite system for two different connecting methods, with discrete and continuously distributed connectors. Dowels are used as discrete connectors and vertically positioned steel sheet in combination with built-in reinforcing mesh was used as a continuous connector with significantly proven advantages compared to the discrete dowel type in the case of reverse cycling loads. Shear tests, as well as full-test of the continuous connector, showed the full-composite behavior of the composite system up to the two-third of failure force which also indicates a possible application of the system at the bridge structures as well. Numerical analysis was performed. Numerical models and laboratory measurements show good matching so the model can be taken as a base for further system optimization and design calculations. Critical review and recommendations for further improvement of this coupling method are presented.
\end{abstract}

Keywords: Timber, EPS, Lightweight Concrete, Composite, Continuously Coupling, Full-Test, FEA Modeling

\section{Introduction}

A composite system based on concrete and timber represents a very successful engineering solution in the process of optimization of construction. The TimberConcrete Composites (TCC) were created between the two World Wars, as a substitute for reinforced concrete slabs due to the lack of reinforcing steel (Rajcic and Zagar, 2000). However, it has not been widely applied until the second half of the century when it proved to be the best solution for existing wooden ceilings renovations due to satisfying the modern demands of load capacity, deformability, fire and seismic resistance and sound insulation.

In the design of TCC, timber element in form of beam or slab has the main role in tension stresses bearing capacity, while the majority of compression stresses is taken by a concrete slab. In this case, reinforcing steel mesh serves to take over the potential tensile stresses in the concrete as well as to reduce the widths of the cracks. Nowadays, by combining different timber products and concrete classes it is easy to achieve improved engineering features for elements in different static systems or load cases. Therefore, it is not uncommon for composite elements to be used in the building of walls, large span slabs, or bridges.

The problem of coupling is complex due to the rheology of materials and coupling methods (from bonding, notches to various types of metal fasteners). To achieve efficient load-carrying capacity, it is necessary to have a sufficiently rigid connection. At the same time, 
the high degree of connector rigidity does not allow the ductile deformation which is not desirable due to the brittle failure of one or both materials in the system. To make TCC competitive in the construction of new structures and bridges, especially with large spans, it is necessary to define optimal connecting methods from an engineering and economic point of view.

This paper presents an overview of the research taking at the Faculty of Civil Engineering, the University of Zagreb to define the behavior of timber-EPS lightweight concrete composite systems. EPS was chosen for several reasons and the leading ones are that EPS is the cheapest of all lightweight concretes. Furthermore, the idea is based on the use of lightweight concrete in older structures that need restoration and strengthening (for instance earthquake areas). Besides, it is also used in new buildings where we want less structural weight for some reason. Finally, it can also find great application in the reinforcement of old bridges that receive a layer of concrete that should not have much weight. Two different connecting methods were tested, with discrete and continuously distributed connectors. All tests were performed for full-scale elements. Numerical analysis was performed as a base for further system optimization and design calculations. Critical review and recommendations for further research are presented.

\section{Experimental Tests of Timber-EPS Lightweight Concrete}

EPS concrete is lightweight concrete with expanded polystyrene admixture which reduces concrete density by $50 \%$ compared to conventional ones. Although with lower density, this kind of concrete has satisfied durability as well as better thermal and acoustic performance. In combination with timber (girders or slabs) EPS concrete makes it possible to create large span composite elements, where this type has sufficient mechanical properties to satisfy the role of concrete in the composite system. However, the fact that EPS concrete has a lower modulus of elasticity (roughly like timber) results in equalizing of the rigidity of concrete timber elements which is an advantage because of more uniform distributed stresses. A significant problem is the lower strengths of the EPS concrete.

The concrete slab and timber beam was observed as a composite system according to Heimeshoff theory (Rajcic and Zagar, 2000). Because of the non-homogeneity of the composite cross-section, due to bending longitudinal slip that occurs between concrete and timber components. Such slip results with shear force carried out by connectors. Numerous methods for connecting are known in the literature. The most researched and in practice the most frequently used are those based on screws or dowels (Rajčić, 2000; Dias, 2005).
Due to the mechanical characteristics differences between conventional and EPS concrete, it is hard to automatically apply existing knowledge. So, determining parameters used for normal concrete is not applicable. Comparing the mechanical and physical properties of concrete with EPS, with other lightweight concretes, it was shown that EPS concrete has a slightly lower compressive strength, however, immersion absorption, capillarity, durability and thermal properties are better in concrete with EPS. Due to their low weight, lightweight concrete opens up surprising constructive possibilities for architects and designers in the design and construction of slender, economically dimensional, yet firmly load-bearing building elements. It is extremely important that recycled EPS is increasingly used. In this way, the impact of this polymer on the environment is reduced and at the same time, we contribute and improve the properties of certain materials, as in this case. To evaluate the performance of timber-lightweight concrete composite systems experimental and numerical research has been done. The behavior of composite elements with discretely distributed connectors and the continuously distributed connector was investigated by laboratory tests as well as by numerical models. All tests were performed in the Structural Testing Laboratory at the Faculty of Civil Engineering, University of Zagreb.

\section{Composites with Discretely Distributed Connectors}

To compare the characteristics of discrete with the continuous type of connection a series of experimental tests with discretely distributed connectors was done. A method often used for renovation because it is economic and simple to prepare and build in, $20 \mathrm{~mm}$ diameter dowels made of smooth reinforcing steel bar were used $\left(f_{y}\right.$ $=240 \mathrm{MPa}, E=200000 \mathrm{MPa}$ ). The original goal of the idea of such a system was to determine the actual loadbearing capacity of already repaired old timber ceilings with smooth bars for which no exact calculation was made. The reason for this was the unknown flexibility of the connection, as well as the modes of fracture of lightweight concrete and timber. It is a connection that has shown sufficient load capacity for normal static and quasi-static loads and is also an economically good solution (Steinberg et al., 2003). The connector was punched in a predrilled $18 \mathrm{~mm}$ diameter hole coated with an epoxy adhesive layer. To define material properties, standard tests for concrete and timber was done. They proved that EPS lightweight concrete belongs to class LC16/18 according to the standard HRN (EN 206, 2016) and density class D1,6 in accordance with EN 12390-7, with an elasticity modulus of $E_{c, m}=18000 \mathrm{MPa}$ and compression strength $f_{c, k, c u b e}=18,5 \mathrm{MPa}$. According to (EN 338, 2016) tests on solid timber samples proved average elasticity modulus of $\mathrm{E} 0$, mean $=11000 \mathrm{MPa}$ with bending strength of $f_{m, k}=24 \mathrm{MPa}$ and tensile of $f_{t, 0, k}$ $=14 \mathrm{MPa}$ and density of $350 \mathrm{~kg} / \mathrm{m}^{3}$. 
To evaluate the performance of slab-beam connectors, the push-out test, as well as the shear test, could be done. To determine the slip modulus as an indicator of the coupling degree the shear test on five small samples was undertaken. The shear test specimen as shown in Fig. 1, was configured, taking into account the size of elements in the full-scale specimen with a concrete slab thickness of $80 \mathrm{~mm}$ and timber girder cross-section of $100 \times 200 \mathrm{~mm}$. Two connectors were punched in a $480 \mathrm{~mm}$ long shear specimen, where total length was equal to twice the $240 \mathrm{~mm}$ distance between connectors. Specimen width of $400 \mathrm{~mm}$ was equal to the axial distance between two timber girders. The results of the shear test were given in the form of a force-slip diagram for each specimen. The relevant slip modulus value was taken for deformation of 2,5\%. The mean values obtained by test $\mathrm{F}$ for ultimate force $\mathrm{F}=21,5 \mathrm{kN}$ are: $C=35024 \mathrm{~N} / \mathrm{mm}, k=0,80$ and $\gamma=0,55$. Since there were no visible outside fracture markings, it was found that load-carrying capacity is defined by reaching the concrete compression strength in the area of the half circumference around the dowel. So, the brittle failure mode of lightweight concrete due to reaching concrete embedment strength is valid.
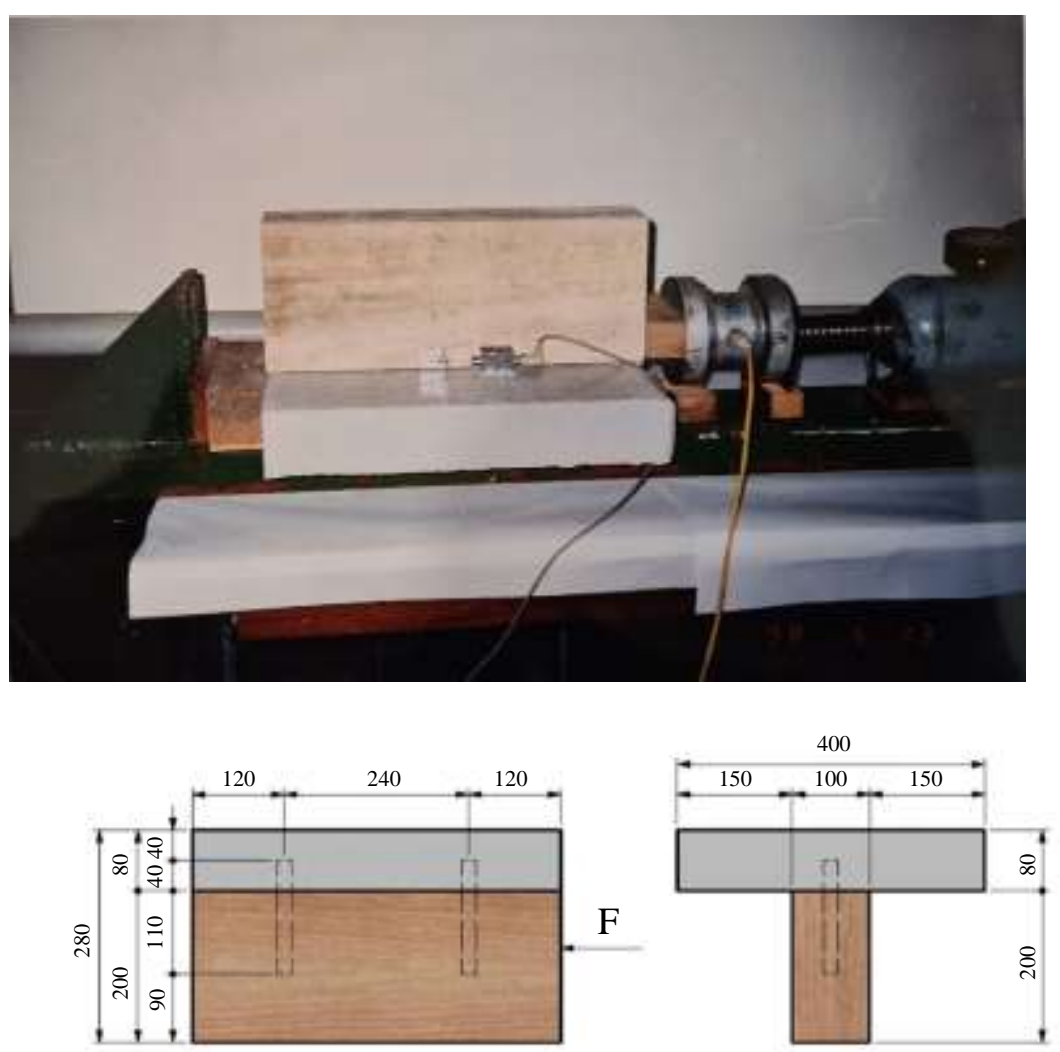

PVC foil
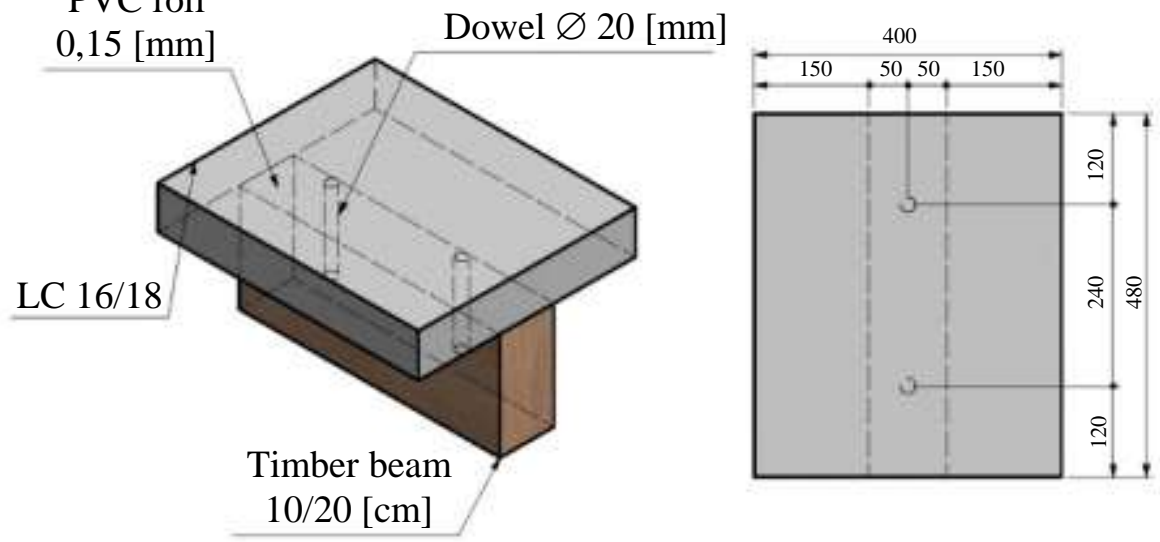

Fig. 1: Shear test specimen with discretely distributed connectors 


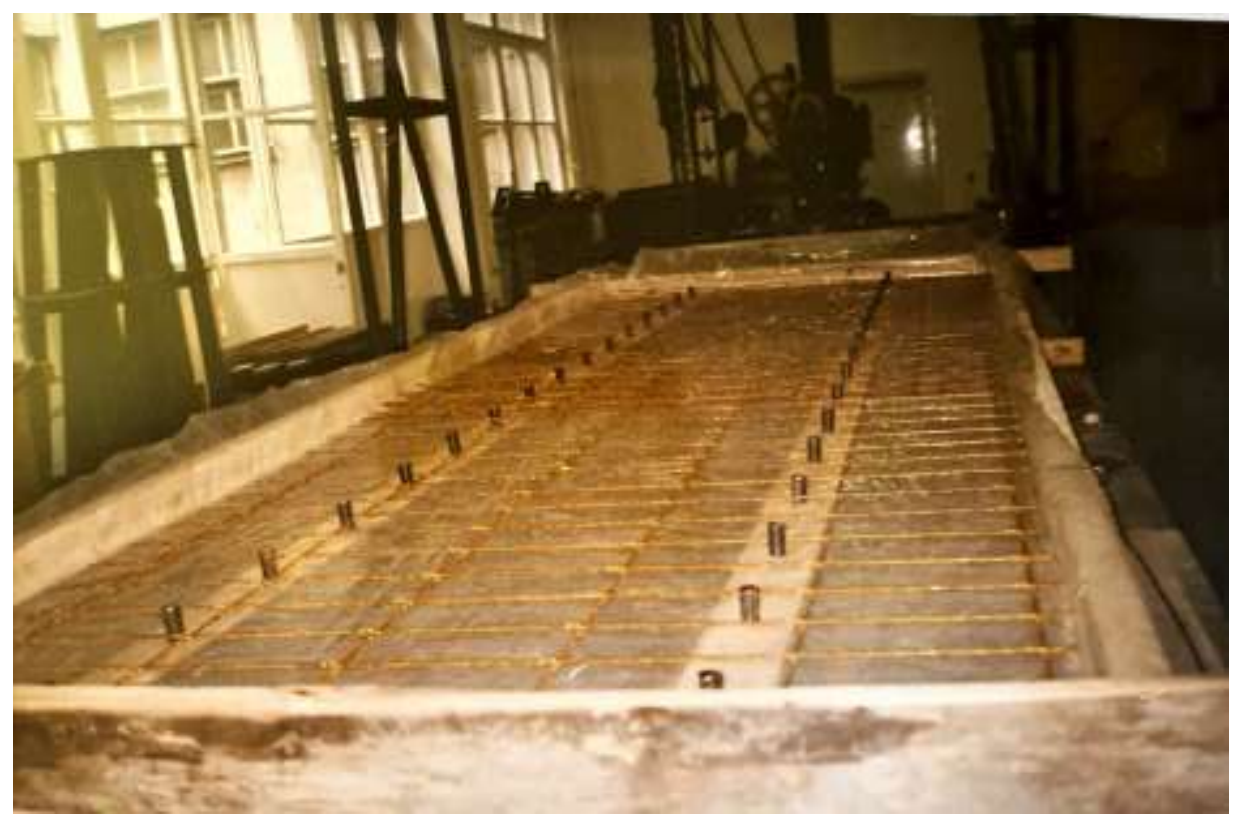

Fig. 2: Shear test specimen with discretely distributed connectors

After shear tests, a full-size specimen shown in Fig. 2 was tested to estimate the performance of the composite element in the real environment. A fourpoint bending test was done. The specimen was composed of two $4000 \mathrm{~mm}$ long timber girders on the axial distance of 710 and $4000 \mathrm{~mm}$ long and $1420 \mathrm{~mm}$ width lightweight concrete slab. As in shear test sample, dowels were distributed along the girder at a distance of $240 \mathrm{~mm}$, where the length of dowel is defined by the center of timber beam on the bottom and center of concrete slab on top of the dowel. According to the background document for the Eurocode 5 (EN 1995-2 Design of timber bridges) published in chapter (Ceccotti, 1995), 'Timber-concrete composite structures', Timber Engineering, Step 2, First Edition, Centrum Hout, The Netherlands, E13/1-E13/12, the spacing of the fasteners was determined by equation $s(e f)=0,75 x s(\min )+0,25 x s(\min )$ where it is known from (EN 1995-1-1, 2008a; 2008b) that minimal spacing is $7 \mathrm{~d}$ and maximal spacing $24 \mathrm{~d}$. The shear specimen is to be designed to have at least two fasteners on effective distance. Also, the distance from the fastener to the edges of the specimen are $s(e f) / 2$. During an assembling specimen was supported all over the length. The specimen was placed on bearings made of concrete $100 \mathrm{~mm}$ width prisms, so that specimen was tested as a simple girder of 3800 $\mathrm{mm}$ span. During the concreting, four tensometers were placed into a concrete slab to collect shrinkage data whereby zero stress conditions were recorded at the end of the concrete. Also, eight inductive tensometers with a base of $100 \mathrm{~mm}$ were used in the middle of the span to measure the stresses through cross-section high. To get deflection data by two LVDT sensors were placed on the edges and in the middle of the span. Four sensors for slip deformation data collecting were placed, respectively.

The loading protocol was divided into two-phase. In the first phase, short-term constant static load up to one-third of the failure load was applied. There was an assumption that due to load and unload cycles for the same level of the load the slip will increase and the stiffness will decrease because the same is happening in composites with a regular concrete slab. So, to register the decrease of the connector stiffness, in the second phase loading with unloading to level $\mathrm{g}$ was applied. Such a load protocol was also interesting to investigate the application of composite elements in bridge constructions not only in-floor systems. In each cycle specimen was loaded with imposed load equal to $q=2,5 \mathrm{kN} / \mathrm{m}^{2}$ in the regime of $q \times n$, where $n=0$; $1 ; 1,5 ; 2 ; 2,5 ; 3 ; 3,5 ; 4$.

Figure 3 shows deflections of the specimen in each load cycle, from which can be seen as a quite significant decrease of the stiffness due to load cycles. To have comparison deflection lines for full-composite action and non-composite action are shown on the graph as well. Regarding slip between the concrete slab and timber beam, the graph in Fig. 4 has a similar shape as a graph for deflection, where is an evident sudden increase of the slip after imposing of $g+2,5 \mathrm{xq}$ load, where the permanent load is $g=1,38 \mathrm{kN} / \mathrm{m}^{2}$.

The stress data in Fig. 5 show that up to a load of $\mathrm{g}$ $+2 \mathrm{xq}$ element has the behavior of full-composite. Above that, load level connector yield rising and the 
element starts to behave as non-composite. For this reason, the tensile stresses in the bottom of the concrete slab rise, as well as the compression stresses on the top edge of the timber girder. Failure starts when the tensile strength of concrete is reached when the load is further transmitted only on a timber beam. Finally, the failure happened when the bottom edge of the timber beam starts cracking. At the span edges, local cracking of concrete is visible such as on shear test specimens.

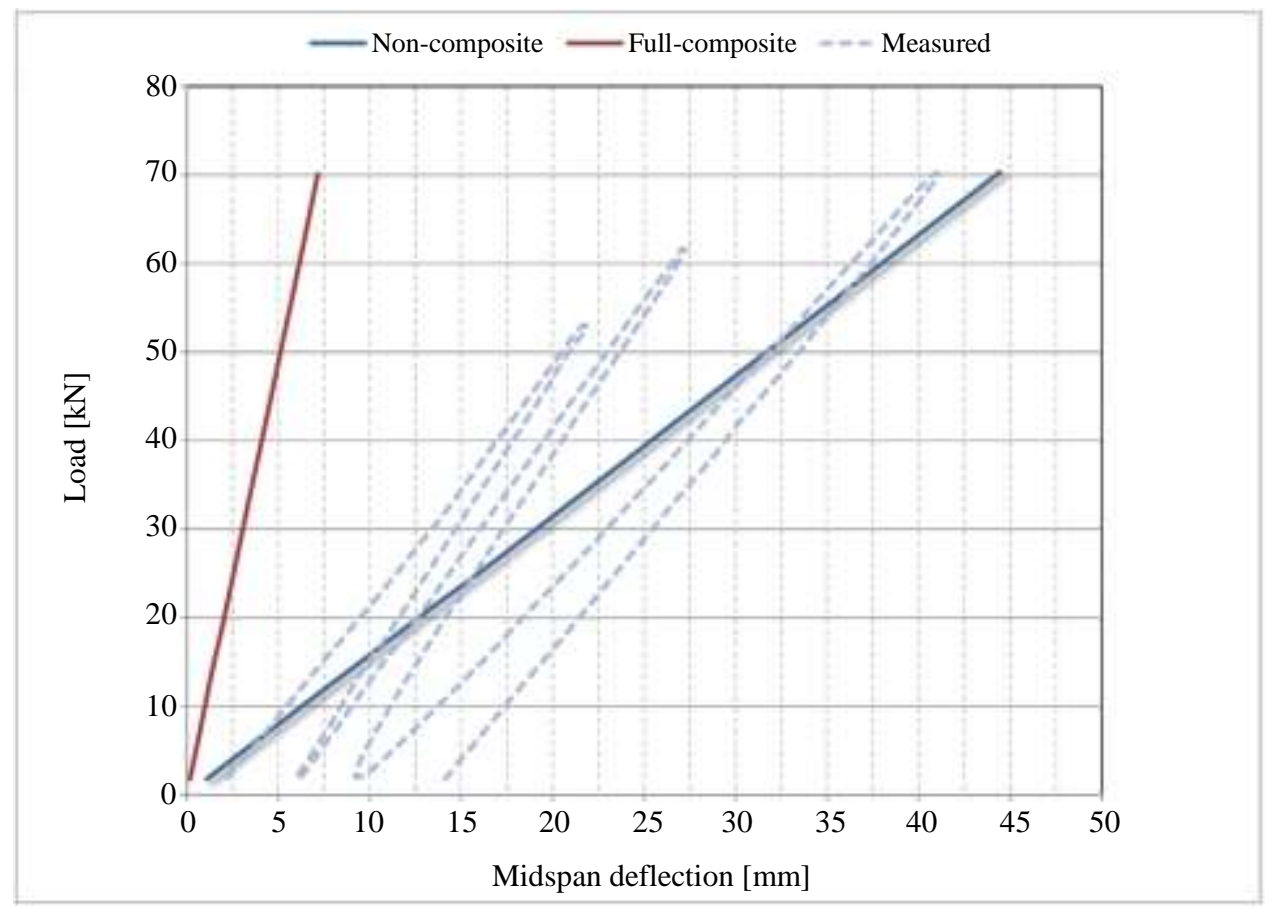

Fig. 3: Deflections of the full-test specimen with discretely distributed connectors

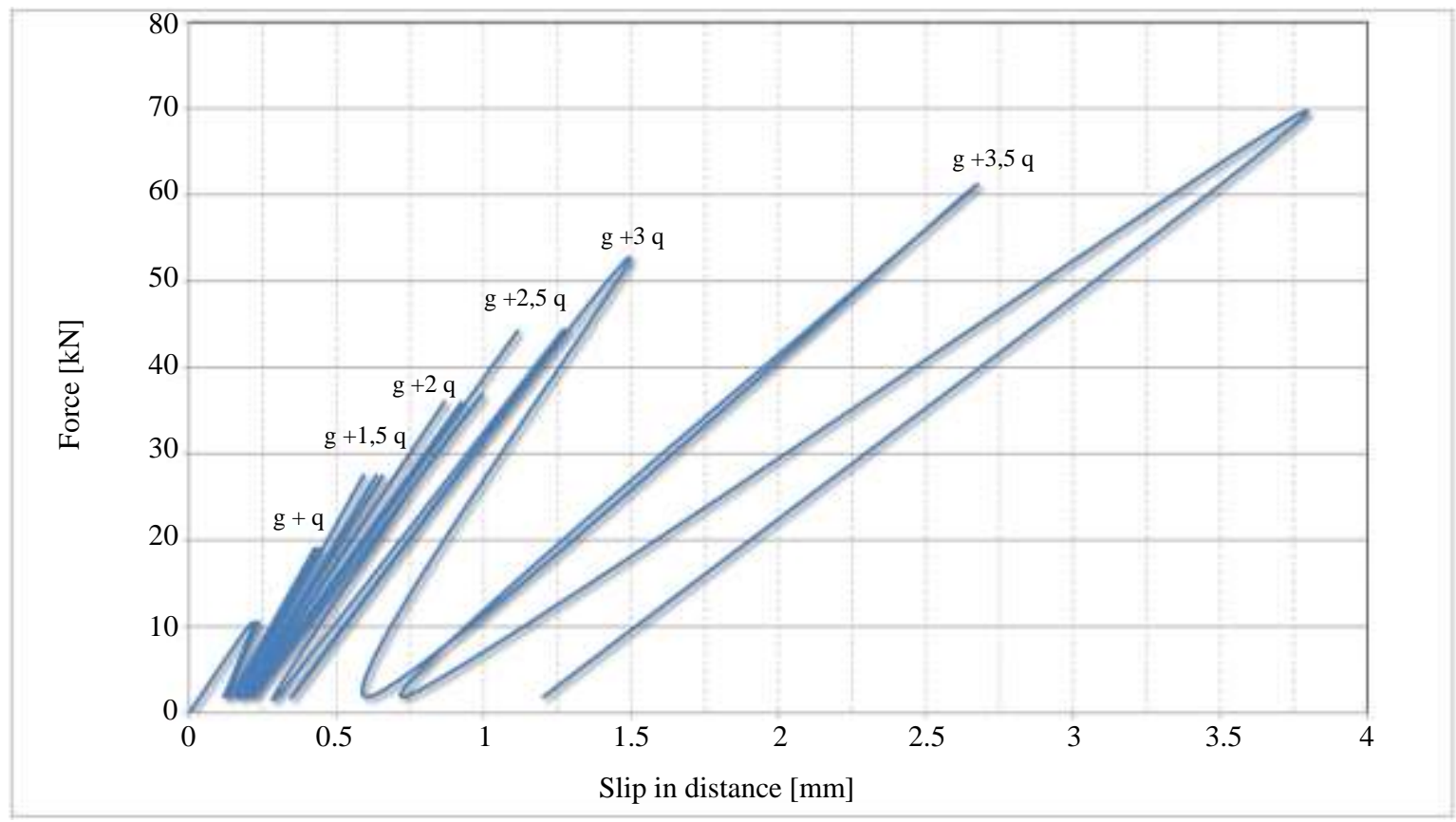

Fig. 4: Slip in the full-test specimen with discretely distributed connectors 

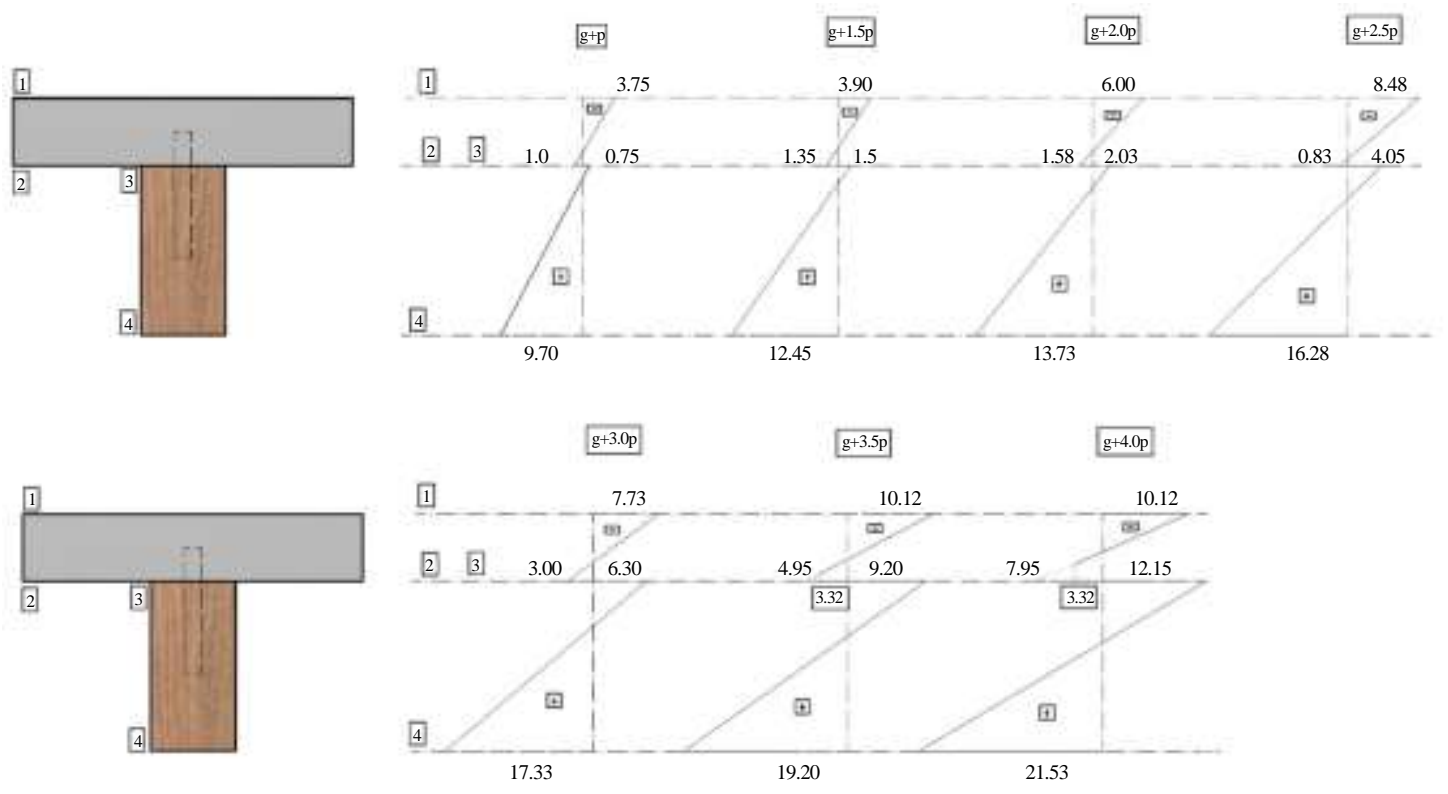

Fig. 5: Stresses in the middle of the span of the full-test specimen with discretely distributed connectors

It can be concluded that timber-EPS lightweight concrete composite with discrete connectors has failed to reach ultimate embedded strength. The concrete slab is locally crushed in contact with steel dowels. Detailed rheological data will be processed, although the basic is visible from (Morlier, 1994; Rajčić, 2000; Jorge et al., 2010).

\section{Composites with Continuously Distributed Connectors}

It is obvious that for timber-lightweight concrete conventional connecting methods can't be used without fear of a significant decrease of the coupling stiffness. The discrete connectors are a good concept and solution under static and quasi-static loads, however, under cyclic loads, the stiffness of such coupling system changes significantly with fatigue. Consequently, in this case, they no longer represent a safe solution. Therefore, for cases like this, continuous connection proved to be a much better coupling system. The profiled steel sheet was applied as a connector. The idea was to put the lower half of the steel sheet into a predrilled slot coated with an epoxy adhesive layer and upper half profile in a way to cut out the grooves in places where the reinforcing mesh is placed. The advantage of this type of connector is that shear force is continuously absorbed not only through the contact between two materials but also by the effective width of the concrete slab over the reinforcing mesh. For the first specimen, a steel sheet $\left(f_{y}\right.$ $=235 \mathrm{MPa}, E=210000 \mathrm{MPa}$ ) with a thickness of 1,2 $\mathrm{mm}$ was used, but the shear test showed that the reinforcing mesh easily dents into the sheet what is shown in Fig. 6. Although the average value of the $\gamma$ coefficient was increased to 0,63 , tests were continued on samples with steel sheet with $2 \mathrm{~mm}$ thickness. In this case, a significant increase of slip modulus was noticed because reinforcing mesh could not penetrate such a solid sheet.

With selected steel sheet, five shear test shown in Fig. 7 was undertaken. Specimens had the same dimensions as ones used for discretely distributed connectors so that the results could be compared. The relevant slip modulus value was taken for deformation of 2,5\%. The mean values obtained by test $F$ for ultimate force $F=57 \mathrm{kN}$ are: $C=252200 \mathrm{~N} / \mathrm{mm}, k=0,25$ and $\gamma=0,80$. Loadcarrying capacity is defined by reaching the concrete ultimate shear strength when the steel sheet starts to cut the concrete slab. In Fig. 8 is obvious that this type of connector has significantly higher connection stiffness compared to discretely distributed dowels.

The full-size specimen showed in Fig. 9 with the continuous type of connector, with the same dimensions and a static system like the one with dowels, was tested on four-point bending. According to HRN (EN 206, 2016) tests proved that EPS lightweight concrete belongs to LC16/18 class and density class D1,6 in accordance with EN 12390-7, An average elasticity modulus is $E_{c, m}=$ $18000 \mathrm{MPa}$, density of $1560 \mathrm{~kg} / \mathrm{m}^{3}$ and compression strength $f_{c, k}$, cube $=18,5 \mathrm{MPa}$. New timber elements were delivered for this test, however, it was found that the same class of wood as in the previous experimental study with the small specimens. Therefore, tests on solid timber samples proved average elasticity modulus of E0, mean $=11000 \mathrm{MPa}$ with bending strength of $f_{m, k}=24 \mathrm{MPa}$ and tensile of $f_{t, 0, k}=14 \mathrm{MPa}$. 


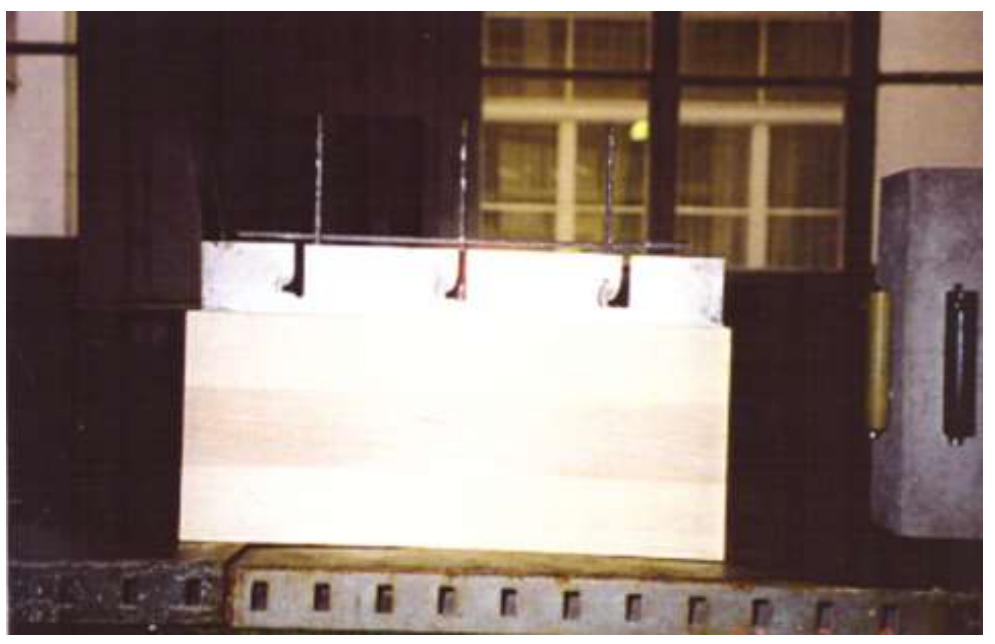

Fig. 6: Shear test specimen with deformed 1,2 mm thick steel sheet

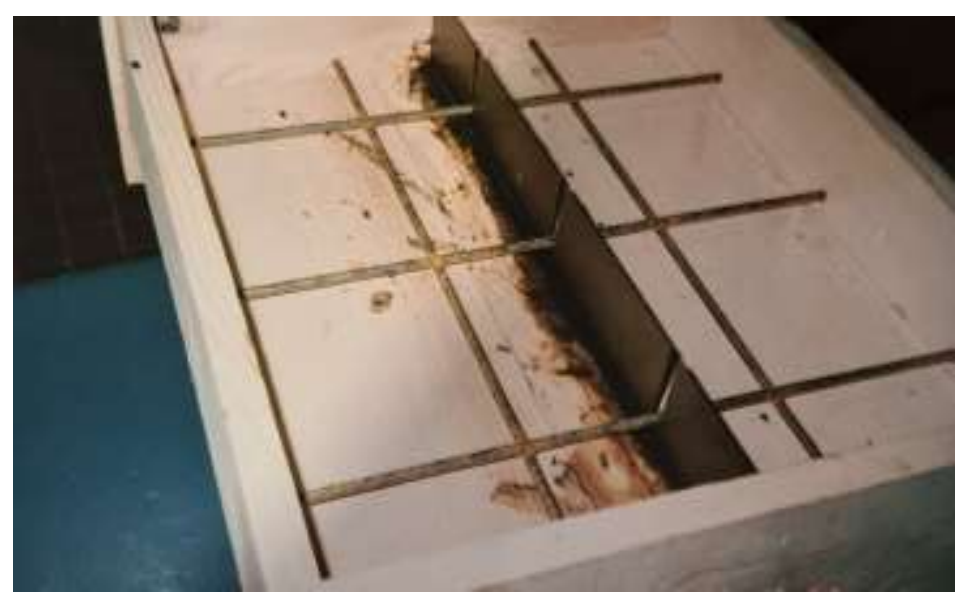

Fig. 7: Shear test specimen with $2 \mathrm{~mm}$ thick steel sheet

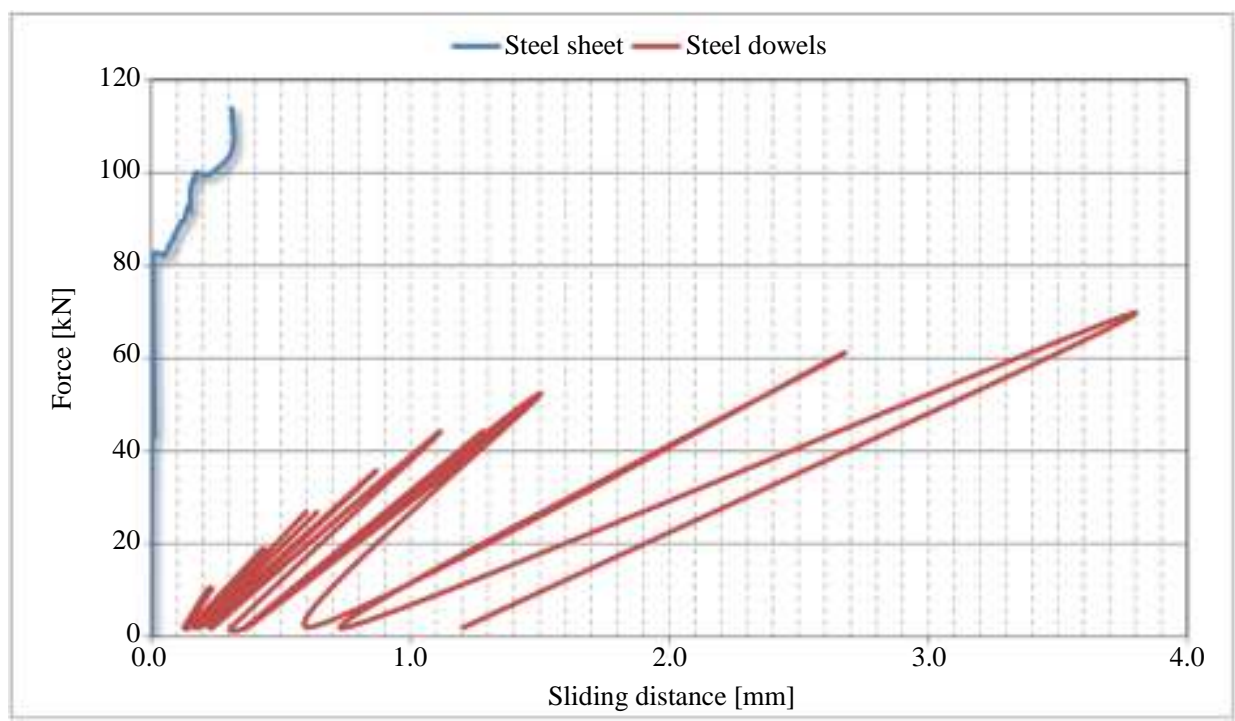

Fig. 8: Comparison of slip for full test specimen with discrete distributed connectors and specimen with 2 mm thick steel sheet 


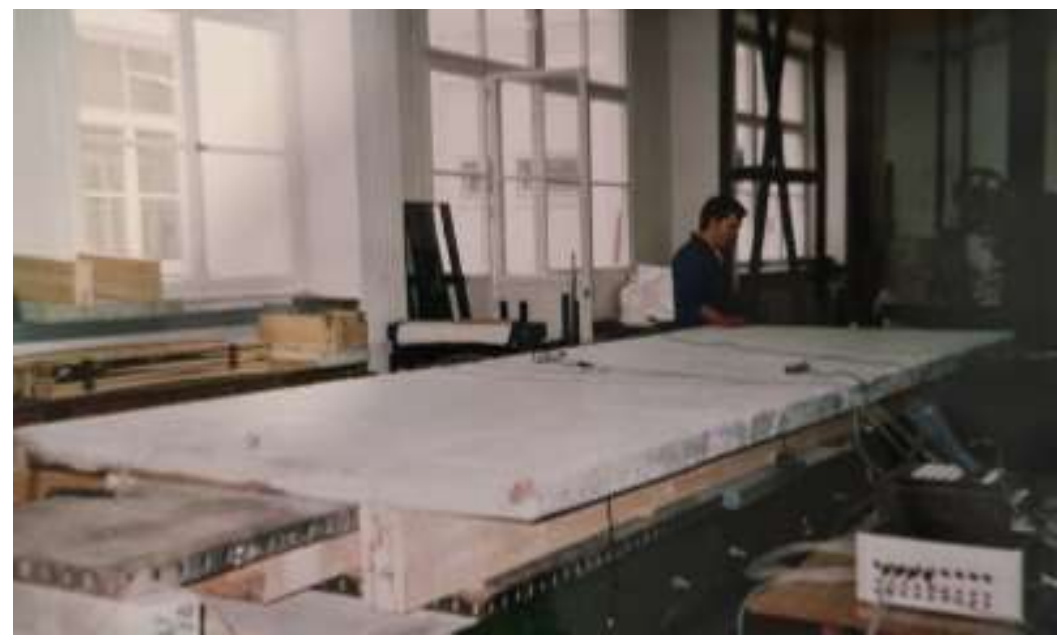

Fig. 9: Full-test specimen with $2 \mathrm{~mm}$ thick steel sheet

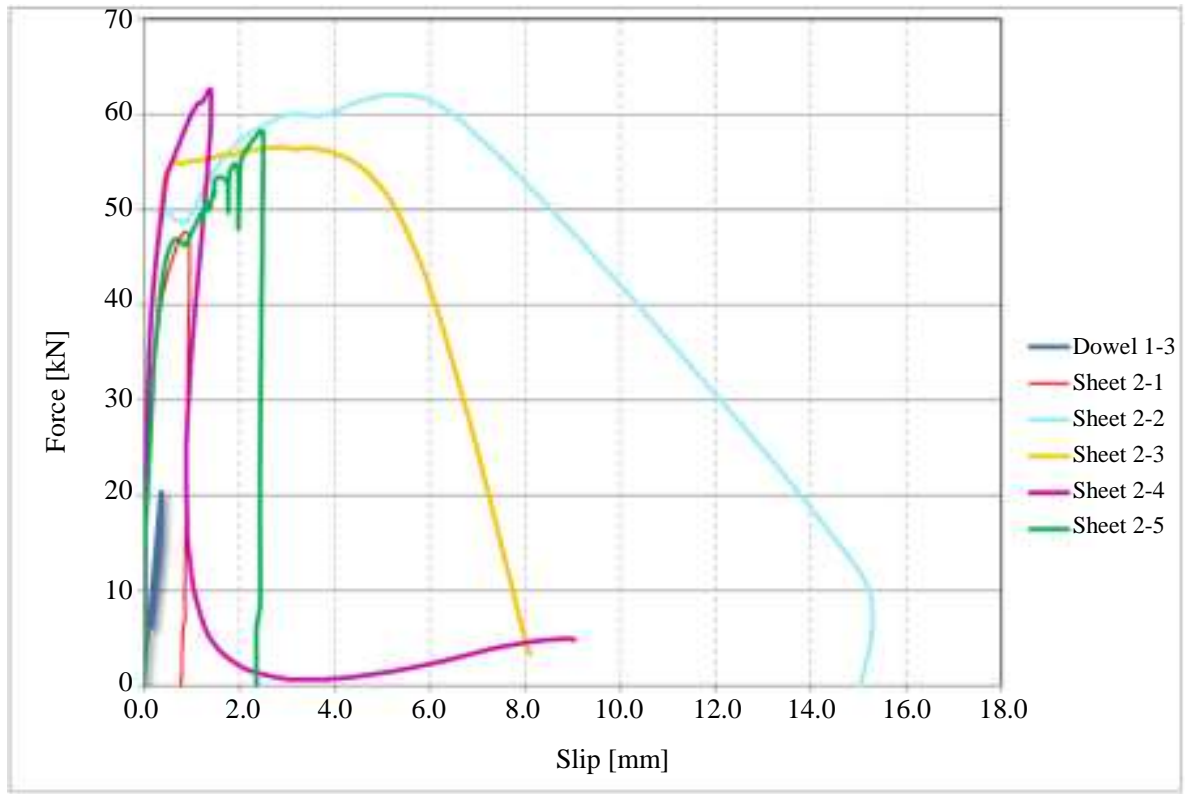

Fig. 10: Comparison of slip for a full-test specimen with discrete distributed connectors and specimen with $2 \mathrm{~mm}$ thick steel sheet

During the test, eight inductive tensometers with a base of $100 \mathrm{~mm}$ were used in the middle of the span to measure the stresses in the characteristic points with maximum stress. Four inductive tensometers with a base of 200 $\mathrm{mm}$ are symmetrically positioned at the contact of the timber beams and slab to measure the slip. The same role has two LVDT sensors were placed on the span edges. To get deflection data by two LVDT sensors were placed on the edges and in the middle of the span.

Load protocol was again divided into two-phase. In the first phase, short-term constant static load up to onethird of the failure load was applied. This was repeated two more times. As no slip was noticed during those cycles of deformation, for the next phase constant deformation increase procedure of loading was accepted. The total load duration was approximately $33 \mathrm{~min}$.

Regarding the slip shown in Fig. 10 between concrete slab and timber beam and deflection, respectively, it is evident that up to two-thirds of the failure force element has the behavior of full-composite. Also, the stress data in Fig. 11 show that up to the imposing load of $g+3,5$ $\mathrm{xq}$ there is no discontinuity in the stresses on contact between two materials. Above that, the load level connection slips rise. Failure starts when the shear strength of concrete is reached when vertical cracks started to spread from the upper edge of the steel sheet to the upper edge of the concrete slab. In the end, it results in the slab splitting from the edges to the center of the slab in the middle of the span. 

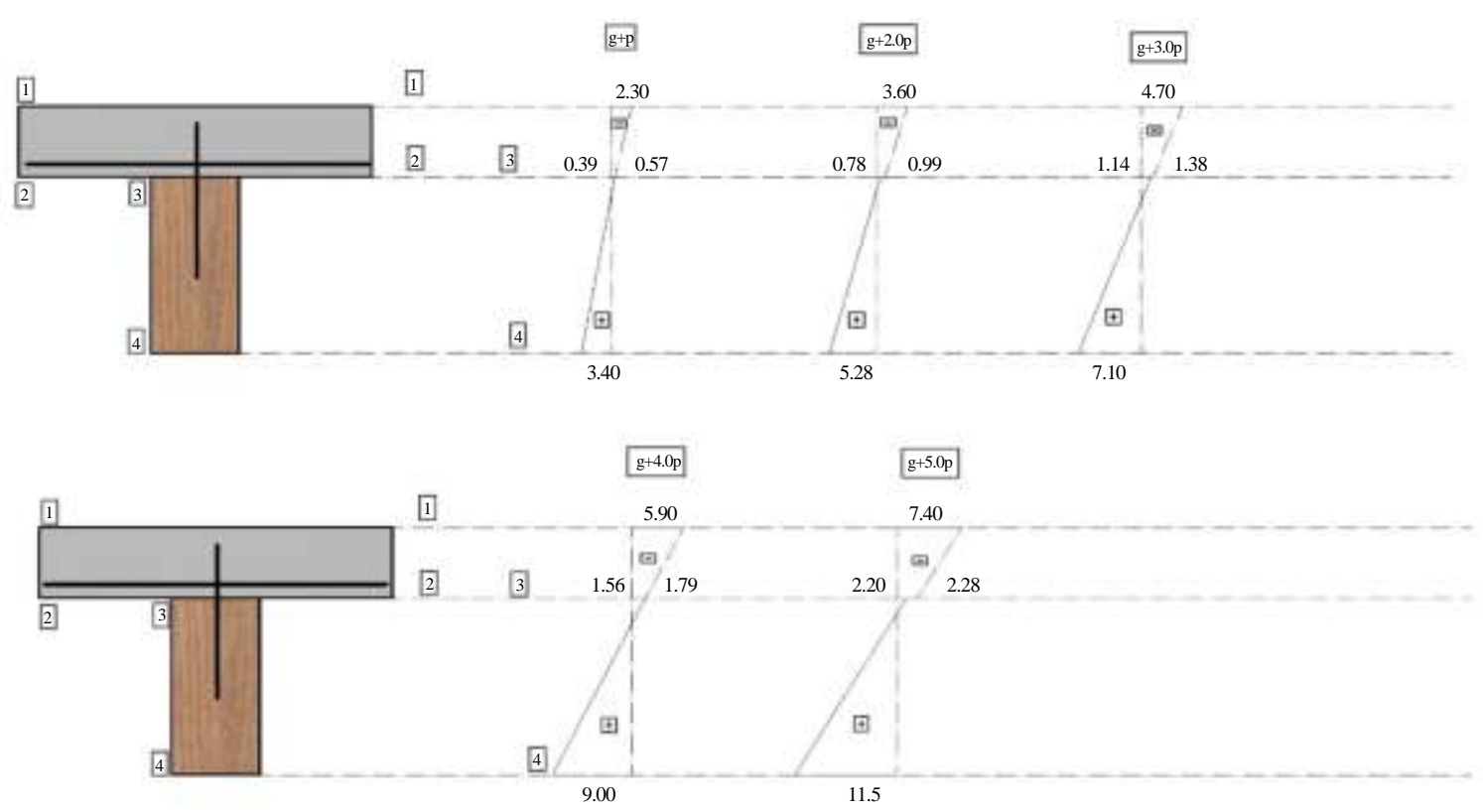

Fig. 11: Stresses in the middle of the span of the full-test specimen with discretely distributed connectors

This test has presented a fact that discretely distributed connectors are a good solution for situations where cyclical loads and fatigue do not occur. Respectively, appropriate methods for such loads should be based on continuously distributed connectors. Other researches on the same topic confirms it. Silva Marques et al. (2020) it was concluded that the increase of load level in the cyclic tests affected the performance of the connection, leading to a decrease in stiffness. Although mechanical connectors such as coach screws, nails, dowels, etc. inserted in the timber without glue are considered to be a simpler way to fasten the concrete slab to the timber beam, they have the disadvantage of being quite flexible and, therefore, requiring a large number of connectors (Fragiacomo et al., 2018).

\section{FE Model for a Full-Test Specimen with 2 mm Thick Steel Sheet}

By choosing EPS lightweight concrete, large differences in stiffness between concrete slabs and timber beams will be reduced, respectively, more uniform distribution of stresses will be achieved by the height of the cross-section of the composite girder. Apart from the more favorable ratio of the modulus of elasticity, the weight of the girder is significantly reduced.

The goal was to find such a fastener that is economical, easy to install and that provides sufficient stiffness between the two materials.

The problem of timber and lightweight concrete coupling was researched thoroughly, starting with extensive testing of timber and concrete characteristics. Moreover, numerous studies related to this research have been carried out at the University of Civil Engineering in Zagreb.

The model represents a realistic segment of ceiling construction, with two timber beams and a reinforced lightweight concrete slab. The coupling has been achieved by using a continuous metal sheet thickness of $2 \mathrm{~mm}$. The metal sheet is impressed and glued with epoxy adhesive to the timber beam mortise at a depth of 6 centimeters.

According to the results of the experimental test, the 3D model was created by using commercial software, Autodesk Inventor and Ansys, where is considered elastic and plastic behavior of timber and lightweight concrete as well as a fastener.

The model reflects a realistic situation and is made in detail, including the modeling of the timber, concrete, reinforcement, sheet metal and the adhesive. Figure 12 shows the details in the $3 \mathrm{D}$ model.

The timber beam and reinforced EPS concrete were modeled as SOLID elements, while sheet metal and the epoxy adhesive were modeled as SHELL elements. Shell elements decouple the deformation on the surface and the deformation in the normal direction, allowing for a simple and efficient simulation of a thin structure. Of course, each of the elements is associated with physical and mechanical properties obtained from the experimental tests it as shown in the following Table 1.

The most demanding part of the modeling was to correctly define the contact regions. Contact between two objects is one of the most frequently encountered phenomena in engineering analysis. In this complex finite element model, there are over 300 contact regions and if 
one of them is not properly defined, the results will largely deviate from the results of experimental testing.

The contact region between timber and concrete was defined as frictionless, according to the laboratory tests of specimens, in which PVC foil was set between these two materials. No penetration is allowed, but surfaces are free to slide and separate without resistance.

After a survey of settings for a contact pair between the faces of two surface bodies, observing stress, deflection, contact and force reaction results in a large displacement model, it was found that satisfactory results were seen when a face-to-face contact pair between the surface bodies were set to bond. It was created bonded contact pair between concrete and the following elements; reinforcement and sheet metal. Accordingly, the contact pair between surface body faces of epoxy adhesive with other elements (timber and sheet metal) was also defined as bonded.

Table 1: Physical and mechanical properties of the elements

\begin{tabular}{|c|c|c|}
\hline \multicolumn{3}{|l|}{ Lightweight LC16/18 concrete } \\
\hline Density & $1,56 \mathrm{e}-006$ & $\mathrm{~kg} \mathrm{~mm}^{-3}$ \\
\hline Maximum tensile pressure & -4 & $\mathrm{MPa}$ \\
\hline Fracture energy & 0,1 & Gf $\mathrm{mJ} \mathrm{mm}^{-2}$ \\
\hline Young's modulus & 18500 & $\mathrm{MPa}$ \\
\hline Poisson's ratio & 0,18 & \\
\hline Bulk modulus & 9635,4 & $\mathrm{MPa}$ \\
\hline Shear modulus & 7839 & $\mathrm{MPa}$ \\
\hline Compressive ultimate strength & 18,54 & $\mathrm{MPa}$ \\
\hline Tensile ultimate strength & 1,64 & $\mathrm{MPa}$ \\
\hline \multicolumn{3}{|l|}{ Sheet metal } \\
\hline Density & $7,85 \mathrm{e}-006$ & $\mathrm{~kg} \mathrm{~mm}^{-3}$ \\
\hline Specific heat & $4,34 \mathrm{e}+005$ & $\mathrm{~mJ} \mathrm{~kg}{ }^{-1} \mathrm{C}^{-1}$ \\
\hline Young's modulus & $2, e+005$ & $\mathrm{MPa}$ \\
\hline Poisson's ratio & 0,3 & \\
\hline Bulk modulus & $1,6667 \mathrm{e}+005$ & $\mathrm{MPa}$ \\
\hline Shear modulus & 76923 & $\mathrm{MPa}$ \\
\hline Yield strength & 235 & $\mathrm{MPa}$ \\
\hline Tangent modulus & 1450 & $\mathrm{MPa}$ \\
\hline \multicolumn{3}{|l|}{ Timber } \\
\hline Density & $3,5 \mathrm{e}-007$ & $\mathrm{~kg} \mathrm{~mm}^{-3}$ \\
\hline \multicolumn{3}{|l|}{ Orthotropic Elasticity } \\
\hline Young's Modulus X direction & 11000 & $\mathrm{MPa}$ \\
\hline Young's Modulus Y direction & 469 & $\mathrm{MPa}$ \\
\hline Young's Modulus Z direction & 746 & $\mathrm{MPa}$ \\
\hline Poisson's Ratio XY & 0,5 & \\
\hline Poisson's Ratio YZ & 0,43 & \\
\hline Poisson's Ratio XZ & 0,45 & \\
\hline Shear Modulus XY & 600 & $\mathrm{MPa}$ \\
\hline Shear Modulus YZ & 50 & $\mathrm{MPa}$ \\
\hline Shear Modulus XZ & 550 & $\mathrm{MPa}$ \\
\hline \multicolumn{3}{|l|}{ Reinforcement } \\
\hline Density & $7,85 \mathrm{e}-006$ & $\mathrm{~kg} \mathrm{~mm}^{-3}$ \\
\hline Specific Heat & $4,34 \mathrm{e}+005$ & $\mathrm{~mJ} \mathrm{~kg} \mathrm{~kg}^{-1} \mathrm{C}^{-1}$ \\
\hline Young's Modulus & $2 \mathrm{e}+005$ & $\mathrm{MPa}$ \\
\hline Poisson's Ratio & 0,3 & \\
\hline Bulk Modulus & $1,6667 \mathrm{e}+005$ & $\mathrm{MPa}$ \\
\hline Shear Modulus & 76923 & $\mathrm{MPa}$ \\
\hline Yield Strength & 500 & $\mathrm{MPa}$ \\
\hline Tangent Modulus & 1450 & $\mathrm{MPa}$ \\
\hline \multicolumn{3}{|l|}{ Epoxy Adhesive } \\
\hline Density & $1,07 \mathrm{e}-006$ & $\mathrm{~kg} \mathrm{~mm}^{-3}$ \\
\hline Coefficient of Thermal Expansion & $5, e+007$ & $\mathrm{C}^{-1}$ \\
\hline Tensile Ultimate Strength & 40 & $\mathrm{MPa}$ \\
\hline \multicolumn{3}{|l|}{ Isotropic Elasticity } \\
\hline Young's Modulus & 1800 & $\mathrm{MPa}$ \\
\hline Poisson's Ratio & 0,4 & $\mathrm{MPa}$ \\
\hline Shear Modulus & 642,86 & $\mathrm{MPa}$ \\
\hline Bulk Modulus & 3000 & $\mathrm{MPa}$ \\
\hline
\end{tabular}




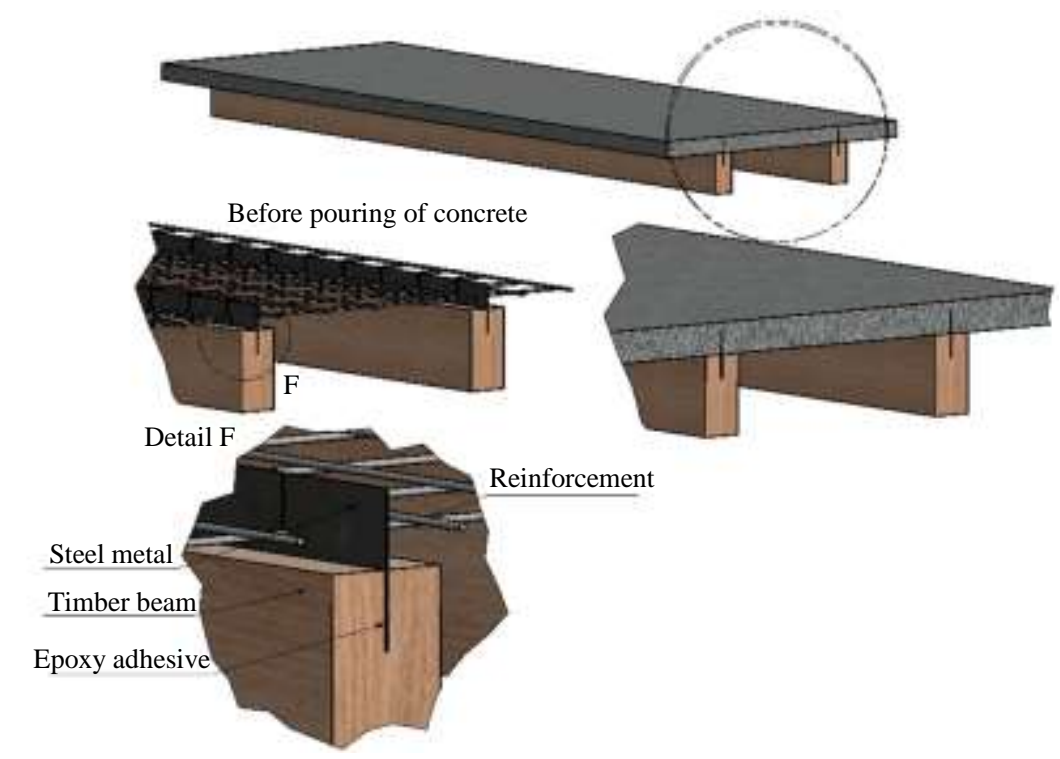

Fig. 12: 3D detailed model

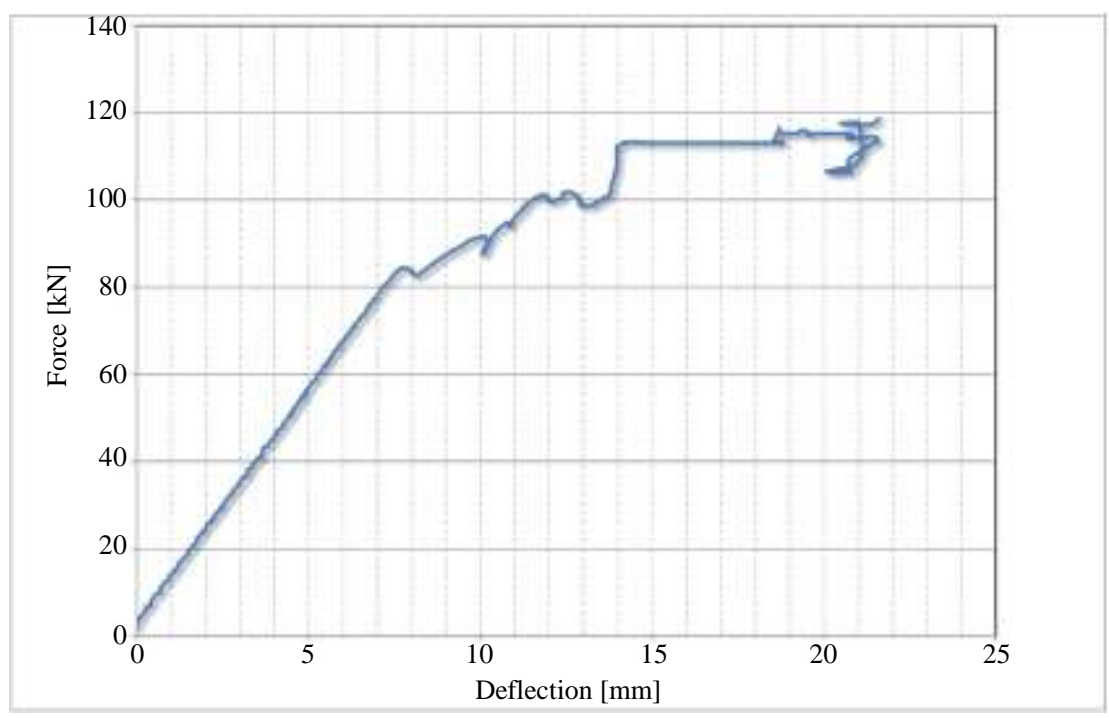

A: Static structural

Total deformation

Type: Total deformation

Unit: $\mathrm{mm}$

Time: 1

25.1.2021. $15: 14$
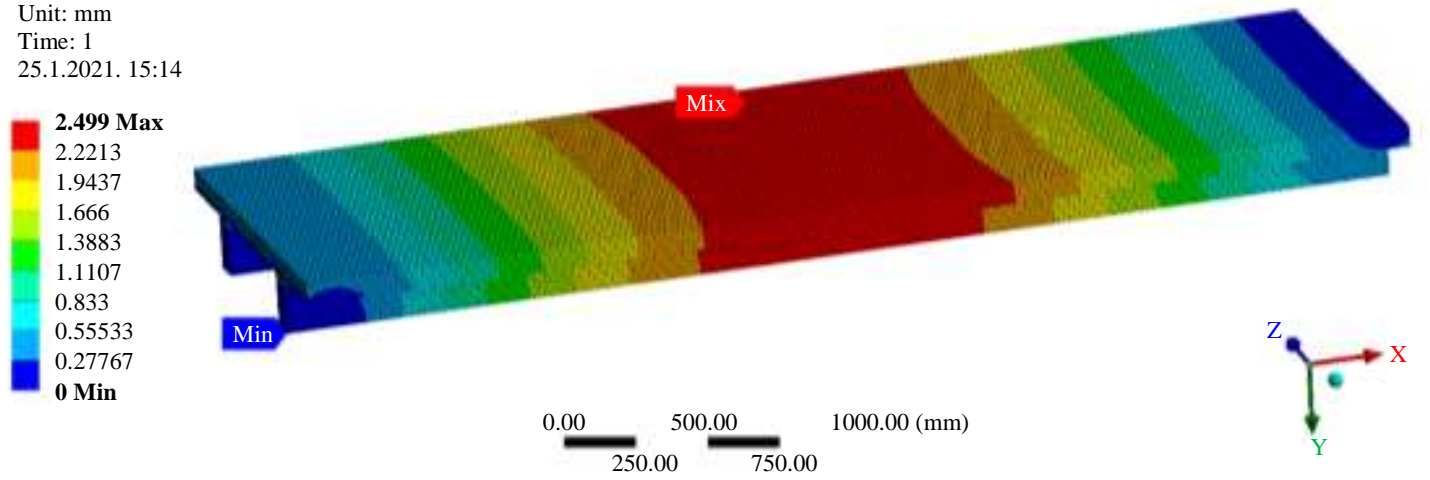

Fig. 13: Comparison of deflection obtained in the experimental tests and FE analysis 
Last but not least, is the frictional contact between sheet metal and reinforcement. It allows sliding with resistance proportional to the defined coefficient of friction, specifically 0.2 .

In the concrete hardening process, the composite girder was supported all over the length. Afterward, the specimen was placed on concrete prisms. Consequently, the final bearing system was simply a supported girder of $3.8 \mathrm{~m}$ span. Likewise, the finite element model was created in software. On the real girded, the load is applied by the hydraulic press over two rails. Following that, it was applied a line load on thirds of the span.

The static analysis was carried out. The results were satisfactory. Correspondence between the results of experimental studies and FE analyses is exceptionally good. Two principal criteria, the ultimate limit state and the serviceability limit state are satisfied. The maximum value of a midspan deflection measured in the laboratory is $2.6 \mathrm{~mm}$. Figure 13 shows that for the same load, the maximum deflection obtained from $\mathrm{FE}$ analysis is 2.5 $\mathrm{mm}$. The result deviation is less than $5 \%$.

Normal stress is dominant in the direction of the longitudinal axis. Figure 14 shows the stress at the upper and lower edge in the lightweight concrete. For a force of $20 \mathrm{kN}$ measured compressive stress is $1.8 \mathrm{MPa}$. FE model shows us very similar values of stress, 1,99 $\mathrm{MPa}$. Deviation in results, in this case, is satisfactory.

By comparing the experimental test results with those from the FEM, Fig. 15 indicates a slight scattering of values for normal stress in the timber beam. nevertheless, the results in the FEM model deviate by less than $15 \%$ compared to the experimental study.
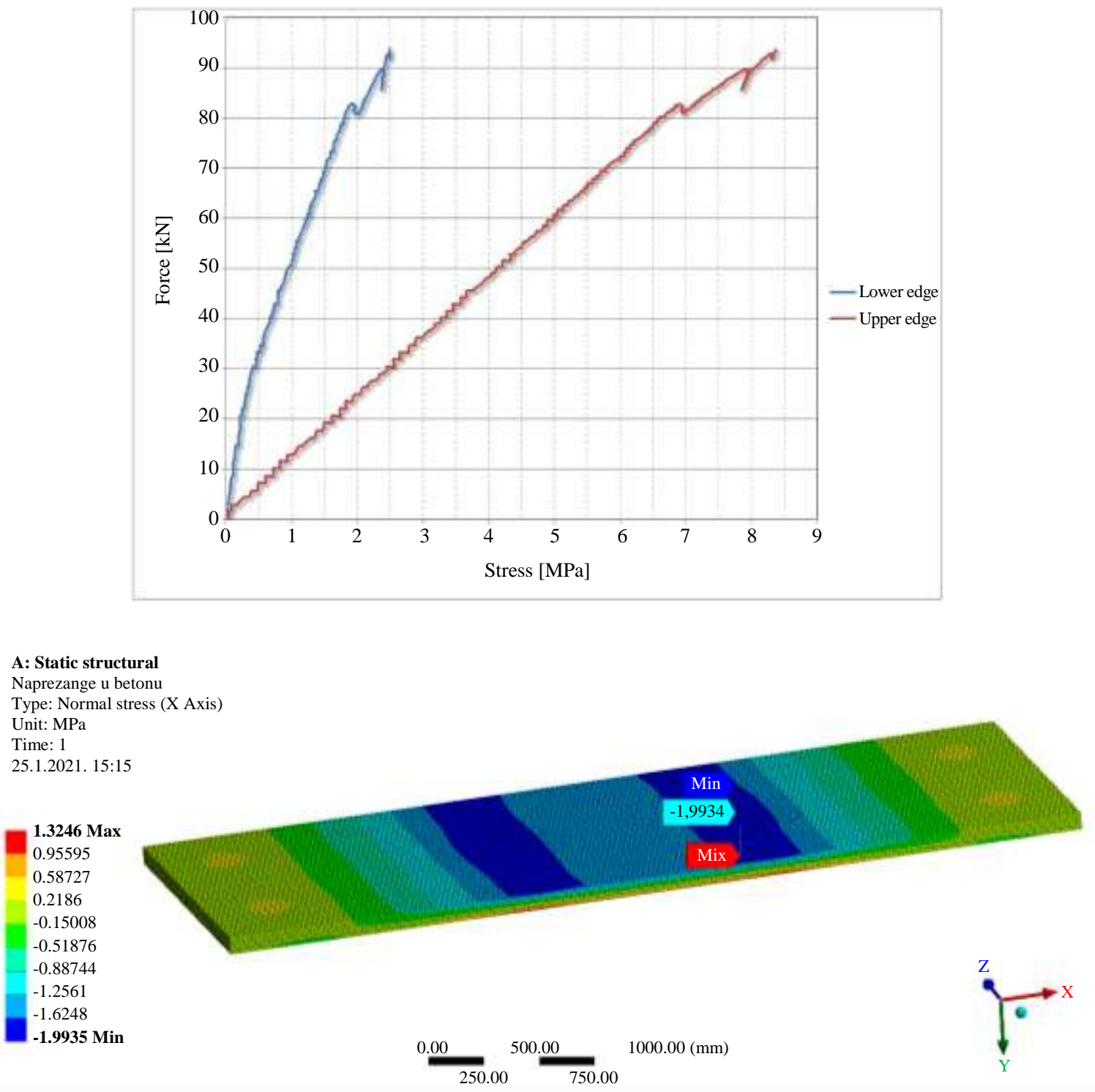

Fig. 14: EPS concrete-comparison of normal stresses obtained in the experimental tests and FE analysis 
Nikola Perković et al. / International Journal of Structural Glass and Advanced Materials Research 2021, Volume 5: 14.28 DOI: 10.3844/sgamrsp.2021.14.28

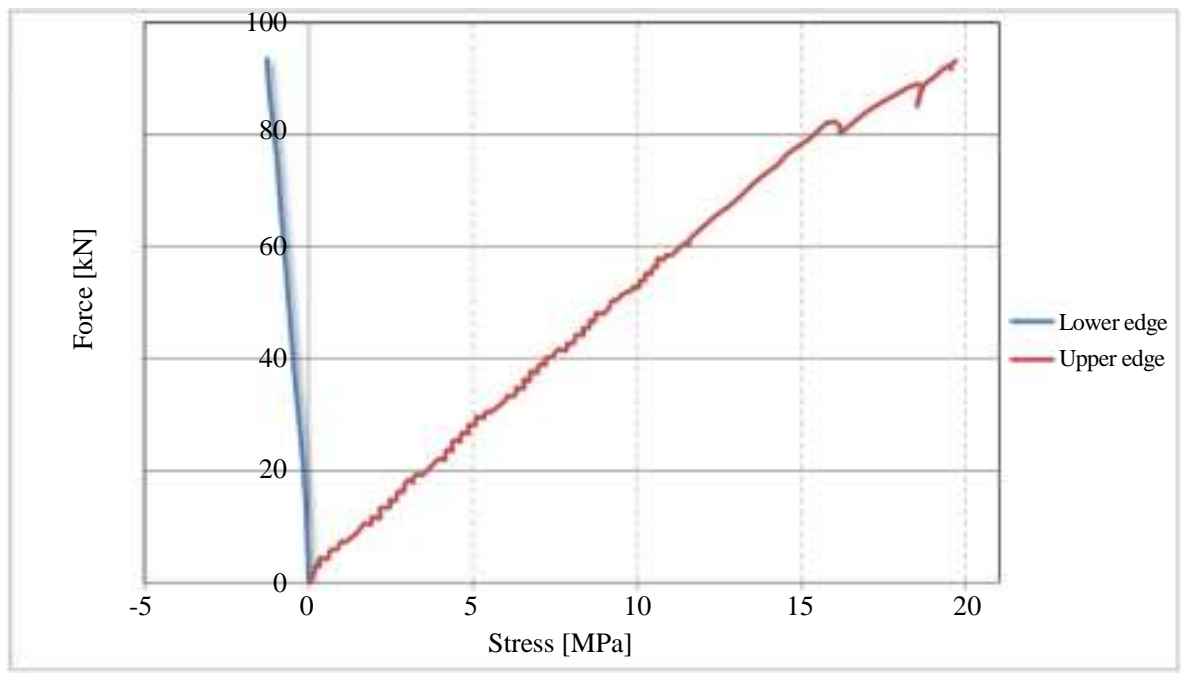

A: Static structural

Naprezange u drvu

Type: Normal stress (X Axis)

Unit: MPa

Global coordinate system

Time: 1

25.1.2021. 15:16

2.7691 Max

1.6128

0.45658

$-0.69967$

$-1.8559$

$-3.0122$

$-4.1684$

$-5.3247$

$-6.4809$

-7.6372 Min

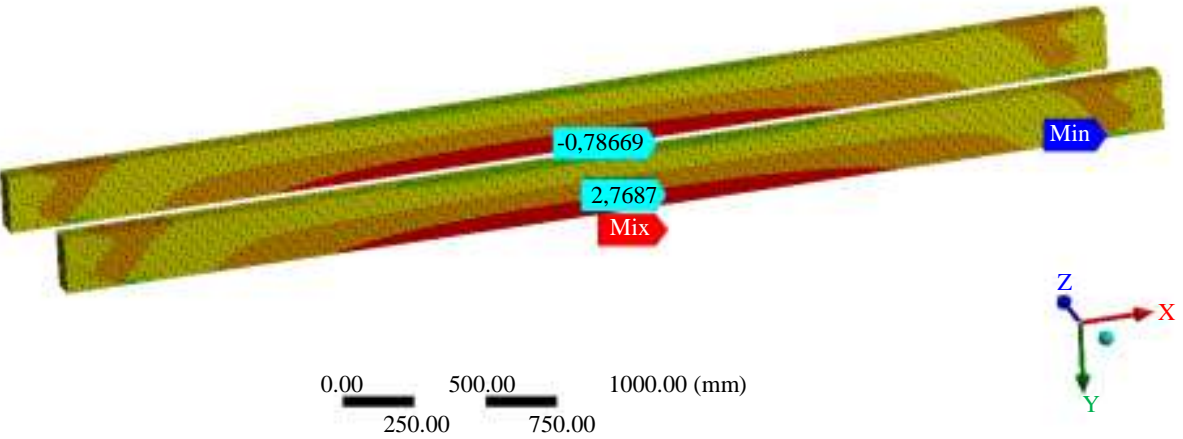

Fig. 15: Timber beam-comparison of normal stresses obtained in the experimental tests and FE analysis

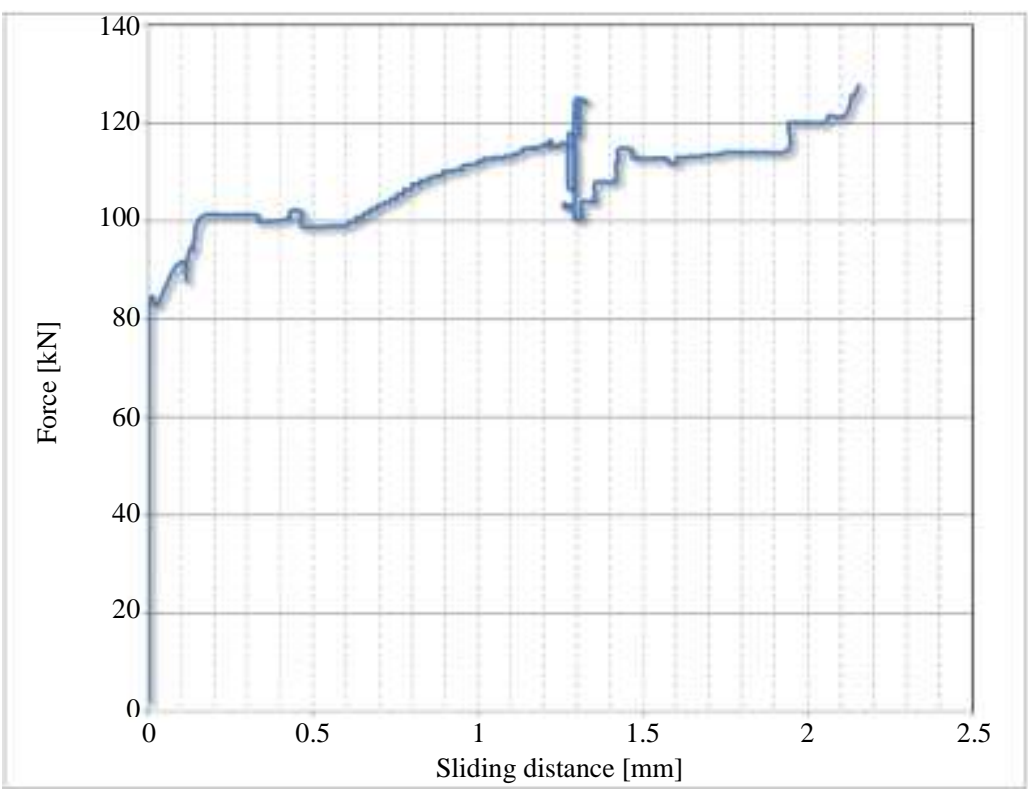




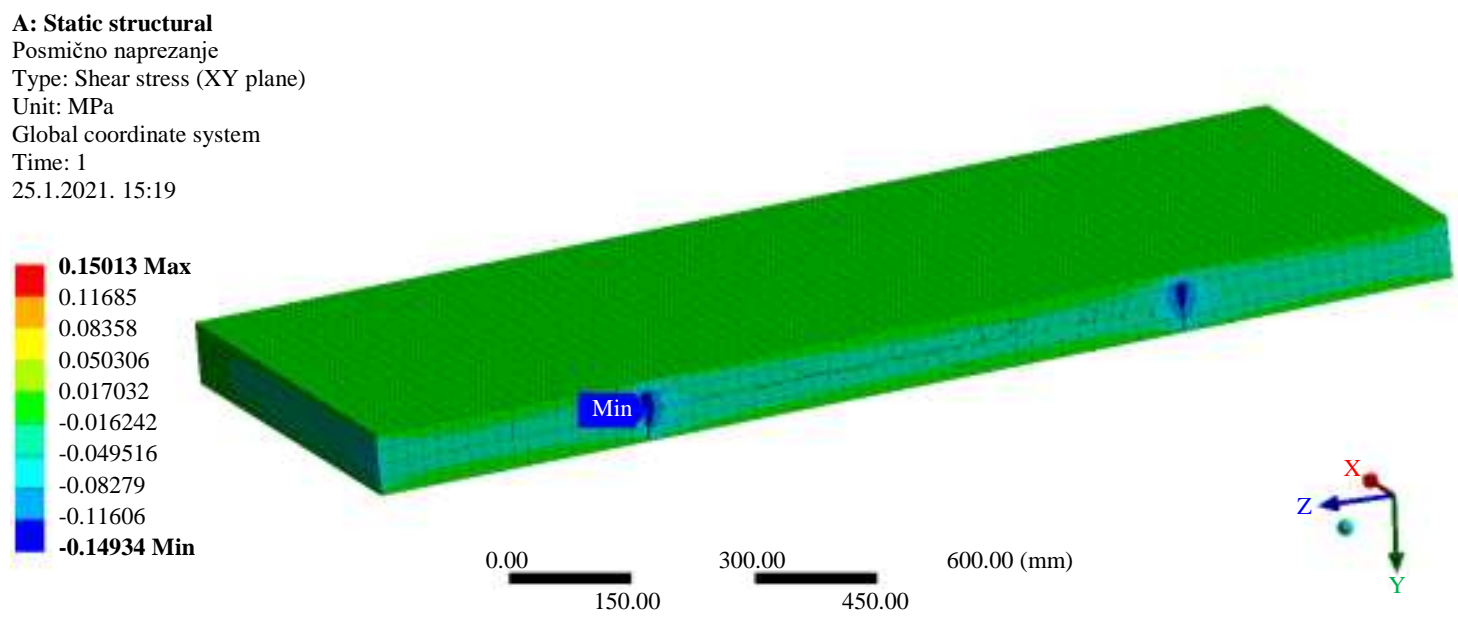

Fig. 16: Shear stress in EPS concrete

This type of connection provides complete and ideal composite action as long as the force value is below 80 $\mathrm{kN}$. Furthermore, after the force reaches a value greater than $66 \%$ of force $(80 \mathrm{kN})$, the slip is almost zero value. For the ultimate $125 \mathrm{kN}$ force, the total sliding distance is $2.2 \mathrm{~mm}$. The loss of bearing capacity occurs at the force of $126 \mathrm{kN}$. The reason for failure is reaching the shear strength of concrete (Fig. 16). This problem can be avoided by bending the upper edge of the sheet into the horizontal position, so the stress concentration would be evaded. Likewise, the depth of penetration of the metal sheet into the concrete slab can be reduced. In that case, there would be a failure as well, but for a much greater force value.

\section{Conclusion}

The results of this research are the design, testing and application of a coupling method for timber-Expanded Polystyrene (EPS) lightweight concrete composite system. Vertically positioned steel sheet in combination with reinforcing mesh has been developed as a continuous connector with significantly proven advantages compared to the standard ones. Tests are shown the full-composite behavior of the composite system up to two-third of failure force which indicates a possible application of the system at the bridge structures or floor structures under cyclic load as well. Because of the complex arrangement, this system is more favorable for new and prefabricated elements where machine processing is available. Further improvement of this coupling method can be achieved by bending of shifting steel sheet protrusion over the reinforcing mesh to the horizontal plane. The steel sheet could have a sinusoidal shape also. With these improvements, the shear area in the concrete slab will increase as well as shear stress concentration in lightweight concrete will be avoided.
Steel sheets can be also perforated to decrease weight. Numerical models and laboratory measurements show good matching. So, further research and optimizations can be performed numerically with a small number of tests that will only serve as model confirmation.

\section{Acknowledgment}

This research was funded by The Ministry of Science and Education of the Republic of Croatia (Project Characteristics of wood-concrete composite system).

\section{Author's Contributions}

\section{Nikola Perković:}

- Writing and editing the whole paper (text, figures, tables), as well as assembling everything into a complete and meaningful work

- Development of numerical model and processing of results, comparative analysis

- Revision and prepared final paper

- Conclusion

\section{Vlatka Rajčić:}

- Idea of research and article, preparation of all test set up, all experimental testings and all measurement data processing of material (wood and EPS concrete), composite shear samples and full scale samples of the composites timber-EPS concrete with discretely and continuous distributed connectors

- Conclusions about behaviour of composite structure timber-EPS concrete

- Final conclusions in article

- Financed all testings 


\section{Jure Barbalić:}

- Introduction and theoretical part of the article

- Assistance in editing of central part of the article

- $\quad$ Figures editing

\section{Ethics}

The authors declare no conflicts of interest. The funders had no role in the design of the study; in the collection, analyses, or interpretation of data; in the writing of the manuscript, or in the decision to publish the results.

\section{References}

Ceccotti, A. (1995). Timber-concrete composite structures. Timber engineering, step, 2(1).

Dias, A. M. P. G. (2005). Mechanical behaviour of timber-concrete joints.

EN 1995-1-1. (2008a). EN 1995-1-1 Eurocode 5: Design of timber structures - Part 1-1: General - Common rules and rules for buildings (EN 1995-11:2004+AC:2006+A1:2008). CEN, Brussels. https://www.phd.eng.br/wpcontent/uploads/2015/12/en.1995.1.1.2004.pdf

EN 1995-1-1. (2008b). EN 1995-1-1 Eurocode 5: Design of timber structures - Part 2: Bridges (EN 19952:2004). CEN, Brussels. https://www.phd.eng.br/wpcontent/uploads/2015/02/en.1995.2.2004.pdf

EN 338. (2016). EN 338 - Structural timber - Strength classes (EN 338:2016). CEN, Brussels. https://standards.globalspec.com/std/10019471/EN $\% 20338$
EN 206. (2016). EN 206 - Concrete - Specification, performance, production and conformity (EN 206:2013+A1:2016). CEN, Brussels. https://infostore.saiglobal.com/preview/2567419377 72.pdf?sku=878211_SAIG_NSAI_NSAI_2087063

Fragiacomo, M., Gregori, A., Xue, J., Demartino, C., \& Toso, M. (2018). Timber-concrete composite bridges: Three case studies. Journal of Traffic and Transportation Engineering (English Edition), 5(6), 429-438.

Jorge, L. F., Schänzlin, J., Lopes, S. M. R., Cruz, H., \& Kuhlmann, U. (2010). Time-dependent behaviour of timber lightweight concrete composite floors. Engineering structures, 32(12), 3966-3973.

Morlier, P. (1994). Creep in timber structures: a report of / Rilem Technical Committee 112-TSC. Rilem. https://trove.nla.gov.au/work/32779579

Rajčić, V. (2000). Karakteristike spregnutih nosača drvolagani beton (Doctoral dissertation, disertacija).

Rajcic, V., \& Zagar, Z. (2000). FEM models of composite timber-lightweight concrete floor systems. In World Conference on Timber Engineering WCTE, Whistler BC, Canada.

Silva Marques, A. F., Martins, C. E. J., \& Geraldes Dias, A. M. P. (2020). Mechanical behavior of dowel connection for timber-concrete composite rural bridges. Maderas. Ciencia y tecnología, 22(1), 69-82.

Steinberg, E., Selle, R., \& Faust, T. (2003). Connectors for timber-lightweight concrete composite structures. Journal of structural engineering, 129(11), 1538-1545. 